\title{
Acute colitis due to methyldopa
}

\author{
Michael Troster, MD, FRCPC, Stephen N. Sullivan. MD, MRCP(UK), FRCPC
}

\begin{abstract}
A case of acute colitis due to antihypertensive therapy with methyldopa is reported. The colonic biopsies showed heavy infiltrates of eosinophils with crypt abscesses, cryptitis and vascular cuffing. Cessation of methyldopa therapy relieved the colitis with recurrence after restarting methyldopa on two separate occasions. Can J Gastroenterol 1989;3(5):182-184
\end{abstract}

\section{Key Words: Colitis, Methyldopa}

\section{Colite aiguë attribuable à la méthyldopa}

RESUME: On rapporte le cas d'une colite aiguë consécutive à un traitement antihypertenseur à la méthyldopa. Les biopsies coloniques révèlent des infiltrations éosinophiles étendues, des abcès cryptiques, une inflammation des cryptes anales et des manchons inflammatoires périvasculaires. La cessation de la thérapie à la méthyldopa a soulagé la colite, qui a récidivé avec la reprise du traitement en deux occasions.
M ETHYLODOPA. ALONE OR IN CONcert with a diuretic, is presently an infrequently prescribed potent antihypertensive drug with several well known pharmacological side effects related to the nervous or cardiovascular system (1); uncommon allergic reactions, such as hepatitis and a Coombs' posi- tive hemolytic anemia, have also been reported (2-6). Even more rarely, an acute allergic colitis, which is reversible with cessation of the methyldopa therapy, has been reported with methyldopa use $(2,3,6-9)$. Herein the clinical and pathological features of a case of methyldopa colitis are described.
Departments of Pathology and Medicine, Victoria Hospital; and the University of Western Ontario, London, Ontario

Correspondence and reprints: Dr Michael Troster, Department of Pathology, Victoria Hospital,

PO Box 5375, London, Ontario N6A 4G5. Telephone (519) 667-6664

Received for publication August 15, 1989. Accepted October 17, 1989

\section{CASE PRESENTATION}

A 71-year-old afebrile woman was admitted to hospital with a four day history of crampy lower abdominal pain and watery green diarrhea. The stool did not contain blood or mucus. The blood pressure was $110 / 45 \mathrm{mmHg}$ with a heart rate of 86 beats $/ \mathrm{min}$. The physical examination was normal. On admission, medications were isosorbide dinitrate $10 \mathrm{mg}$ qid, digoxin $0.25 \mathrm{mg}$ daily, triazolam $0.25 \mathrm{mg}$ at bedtime and alphamethyldopa $250 \mathrm{mg}$ bid. The alphamethyldopa had been started three months previously for the treatment of hypertension.

All medication was stopped and the patient rehydrated. In hospital, she had eight to 10 watery green large volume bowel movements per day, which were negative for occult blood. Investigation revealed a hemoglobin of $11.1 \mathrm{~g} / \mathrm{dL}$ and a white blood cell count of $17,700 / \mathrm{mm}^{3}$ with $98.6 \%$ granulocytes. Stool cultures were negative for campylobacter, salmonella, shigella and yersinia.

By the seventh hospital day the patient had normal formed bowel movements. She remained normotensive, so 


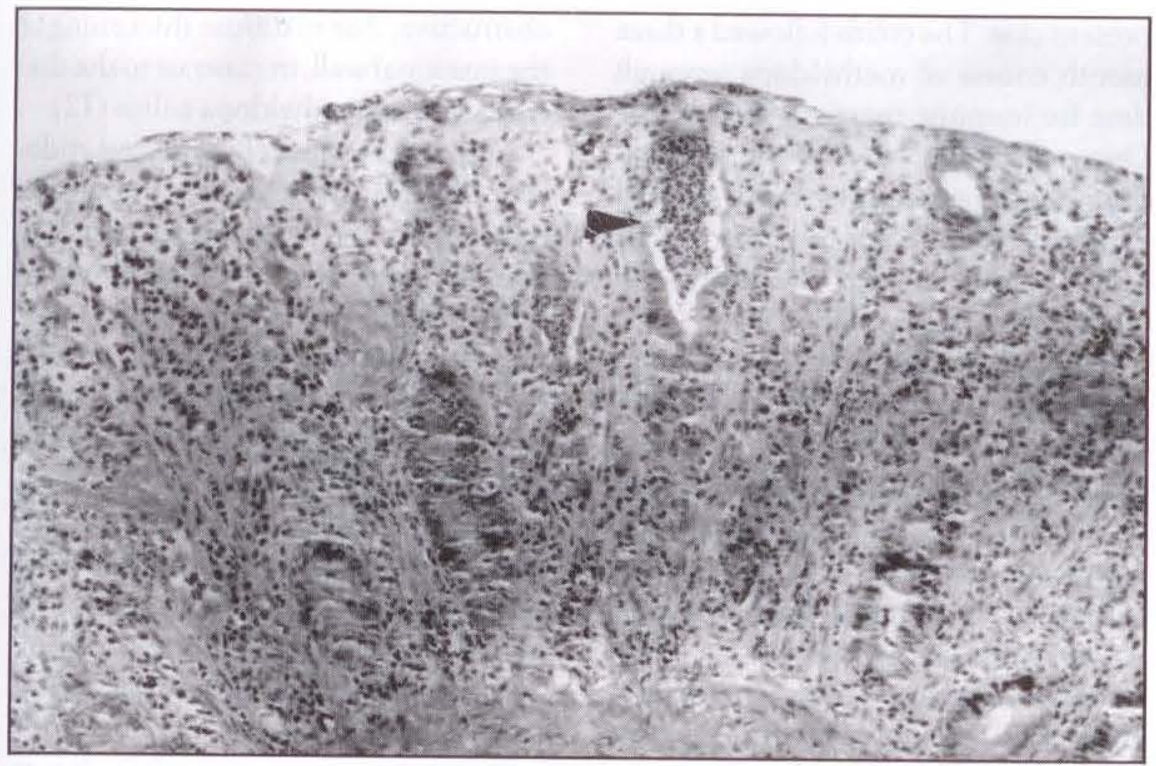

Figure 1) Colonic biopsy showing intense inflammatory infiltrate including crypt abscess formation (arrowhead). Note that the inflammation stops at the level of the muscularis mucosa

the alpha-methyldopa was not restarted. She was discharged with a provisional diagnosis of viral gastroenteritis, more by reason of exclusion than by any specific evidence of viral infection.

Two months later the patient presented to the emergency department with a two week history of diarrhea identical to the previous episode. She had been restarted by her family physician on a combination medication consisting of alphamethyldopa $250 \mathrm{mg}$ and hydrochlorothiazide $25 \mathrm{mg}$ twice daily, because she had been found to be hypertensive in follow-up. On this occasion, a sigmoidoscopy was performed which revealed a very watery, greenish-brown stool without blood or mucus. The rectal mucosa was diffusely erythematous with obliteration of the vascular pattern, but there was no ulceration or contact friability. A rectal biopsy was obtained. Hemoglobin was $12.0 \mathrm{~g} / \mathrm{dL}$, white blood count $11,400 / \mathrm{mm}^{3}$ with $94 \%$ granulocytes and no eosinophils. The zeta sedimentation rate was $0.7 \mathrm{~mm} / \mathrm{h}$ (normal 0.4 to 0.54 ). With the exception of an albumin of 33 $\mathrm{g} / \mathrm{L}$ the remainder of her biochemistry, including liver function tests, was normal. Stool cultures were again negative.

It was felt that the colitis might be related to alpha-methyldopa, and the drug was stopped. Immunological studies were performed. Antinuclear antibody was negative; Coombs' test was negative; IgA and $\operatorname{IgM}$ were all normal. $\operatorname{IgE}$ was 52 $\mathrm{iu} / \mathrm{mL}$ (normal less than 25). Serum $\mathrm{C}_{3}$ was $1670 \mathrm{mg} / \mathrm{L}$ (normal 550 to 1200 ), $\mathrm{C}_{4}$ was $598 \mathrm{mg} / \mathrm{L}$ (normal 200 to 500 ). Total complement $\mathrm{CH}_{100}$ was 130 units (normal 55 to 87 ). The diarrhea rapidly resolved, and one month later the patient underwent flexible sigmoidoscopy at which time the rectosigmoid mucosa was normal. There was marked diverticulosis. A barium enema revealed only uncomplicated diverticular disease.

Three weeks later the patient took a single tablet of the alpha-methyldopa/ hydrochlorothiazide combination because her ankles had become edematous. Within $12 \mathrm{~h}$ diarrhea had returned associated with fecal incontinence. The stool was nonbloody, but there was considerable mucus and crampy lower abdominal pain. A sigmoidoscopy revealed marked erythema of the mucosa. Another rectal biopsy was obtained. The diarrhea resolved and peripheral edema has been controlled with hydrochlorothiazide $50 \mathrm{mg}$ daily. Ischemic heart disease has continued to be treated with isosorbide dinitrate $10 \mathrm{mg}$ qid.

\section{PATHOLOGY}

The rectal biopsies showed inflammation confined to the mucosa (Figure 1). The surface epithelial layer was thinned and infiltrated by eosinophils. Minute superficial aphthous ulcers were also present. Large eosinophilic crypt abscesses were prominent and associated with cryptitis. The epithelial cells lining the crypts were attenuated near the surface of the biopsy, but deeper, toward the muscularis mucosa, the crypt epithelial cells were swollen with pyknotic nuclei. The goblet cell population was markedly decreased. The lamina propria between the crypts showed a mixed infiltrate of plasma cells and lymphocytes. Margination of the blood vessels by eosinophils was prominent (Figure 2).

\section{DISCUSSION}

Since the introduction of methyldopa in 1961, numerous side effects have been reported including fever, hepatitis, pancreatitis, myocarditis and a Coombs' positive hemolytic anemia $(1,5)$. The first reported case of methyldopa-induced colitis by Bonkowsky and Brisbane in 1976 was published about 15 years after the introduction of the drug (2). Since that initial report, 17 cases have been reported in the European and North American literature $(3,8,9)$.

The pathogenesis of the colitis, as well as the hemolytic anemia and hepatitis is not completely explained. The studies of Kirtland and colleagues (10) showed that methyldopa causes increased lymphocytic cyclic AMP resulting in inhibi-

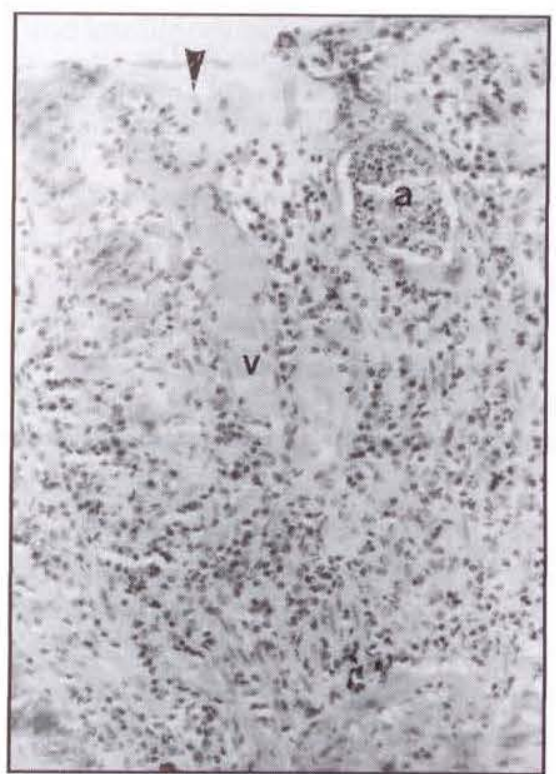

Figure 2) Colonic biopsy showing crypt abscess (a), aphthous ulcers on mucosal surface (arrowhead), and vascular margination with eosinophils (V) 
tion of suppressor T-cell function, which in turn leads to unregulated autoantibody production by B cells. This then results in hemolytic anemia. This mechanism does not, however, explain the colitis. An autoimmune or type III immune reaction would cause decreased complement levels (it was increased in the present case) due to binding by antigenantibody complexes. As well, $\operatorname{lgE}$ which was raised in this patient is not a complement-fixing antibody, whereas $\lg G$ and IgM are. The histological picture in methyldopa colitis is more in keeping with a type I immediate hypersensitivity anaphylactic reaction. The patient becomes sensitized to methyldopa, and re-exposure to the drug causes degranulation of mast cells and basophils mediated by $\operatorname{IgE}$ antibody. The histamine and other factors released from the granules result in smooth muscle contraction and increased vascular permeability which in turn result in diarrhea. The chemotactic factors released account for the large eosinophilic infiltrate seen in the biopsy (11).

A type I hypersensitivity reaction is supported by the clinical history in the

ACKNOWLEDGEMENTS: The authors thank Lynda Milliken and Claire Gunn for secretarial assistance.

\section{REFERENCES}

1. Goodman LS, Gillman A. The

Pharmacological Basis of Therapeutics, 5 th edn. New York: Macmillan Co, 1975:709-26.

2. Bonkowksy HL, Brisbane J. Colitis and hepatitis caused by methyldopa. JAMA 1976;236:1602-3.

3. Lichtenstein H, Henry R, Escure MN, Hautefeuille M, Wilhelm F. Colite iatrogénique par methyldopa. Nouv present case. The colitis followed a three month course of methyldopa, enough time for immune reactions to develop. Onset of colitis after taking methyldopa, both on prescription of the patient's physician and on the patient's own initiative would seem to confirm the methyldopa-colitis relationship.

It would be presumptuous to attempt to delineate specific pathologic features of this condition on the basis of one case. Other than a brief mention of the pathology in the first reported case (2), no other case description mentions pathological findings. Many of the features described such as the eosinophilic crypt abscesses, ulcerated surface epithelium and vascular eosinophilic cuffing suggest inflammatory bowel disease, infective colitis or, although rare in the colon, eosinophilic gastroenteritis in the differential diagnosis, and may be difficult, if not impossible, to distinguish from these other conditions. It would be unusual to see such a great eosinophilic infiltrate in infective colitis or inflammatory bowel disease, but it could be seen in eosinophilic gastroenteritis. The symptoms of eosinophilic gastroenteritis are usually

Presse Méd 1980;9:2349-50.

4. Maddrey WC, Eoitnott JK. Severe hepatitis from rethyldopa. Gastroenterology 1975;68:351-60

5. Mitchell JR, Dybing E, Nelson SD. Metabolic activation of methyldopa by superoxide anion in human liver and erythrocytes. Gastroenterology 1975;69:84-7.

6. Van Gossum A, Michils A, Madhouse PL, Lecocq E. Les entérocolites médicamenteuses. Rev Med Brux 1986:7:163-7.

7. Fortson WC, Tedesco FJ. Drug-induced colitis: A review. Am J Gastroenterol 1984:79:878-83

8. Graham CR, Gallagher K, Jones JK. obstructive, due to diffuse thickening of the intestinal wall, in contrast to the diarrhea seen in methyldopa colitis (12).

The patient's age (71 years) and endoscopic findings of an erythematous mucosa with loss of vascular pattern suggests an ischemic colitis. The histological findings, however, did not show pseudomembrane formation, hemosiderin deposits or fibrosis, as one would expect to see in acute or chronic ischemic colitis. Parasites can cause an intense eosinophilic infiltrate, but the pattern of inflammation such as granuloma formation in schistosomiasis and/or identification of the parasite in the biopsy or stool should help make the diagnosis apparent in most cases.

In summary, a case of colitis due to methyldopa therapy, that recurred following two re-introductions of the drug, has been described. Any hypertensive patient with onset of persistent crampy diarrhea should be questioned as to antihypertensive drug therapy. A history of methyldopa ingestion, together with a heavy eosinophilic infiltration in a colonic biopsy, should confirm the diagnosis of methyldopa colitis.

Acute colitis with methyldopa. N Engl J Med 1981;304:1044-5.

9. Young BA, Girotti MJ. Methyldopa hypersensitivity can mimic acute toxic enterocolitis. Can J Surg 1988; 1: 165-6.

10. Kirtland H, Mohler DN, Horwitz DA. Methyldopa inhibition of suppressorlymphocyte function. N Engl J Med 1980;302:825-32.

11. Rubin E, Forber JL. Pathology, 1st edn. Philadelphia: JB Lippincott Co, 1988:104-6.

12. Morson BC. Eosinophilic enteritis. In: Symmers MW St C, ed. Systemic Pathology, Vol 3, Alimentary Tract. Edinburgh: Churchill Livingstone, 1987:276 


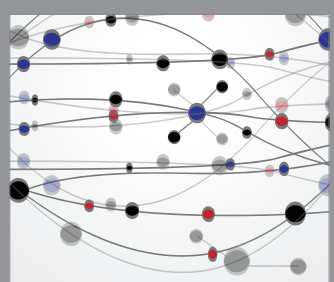

The Scientific World Journal
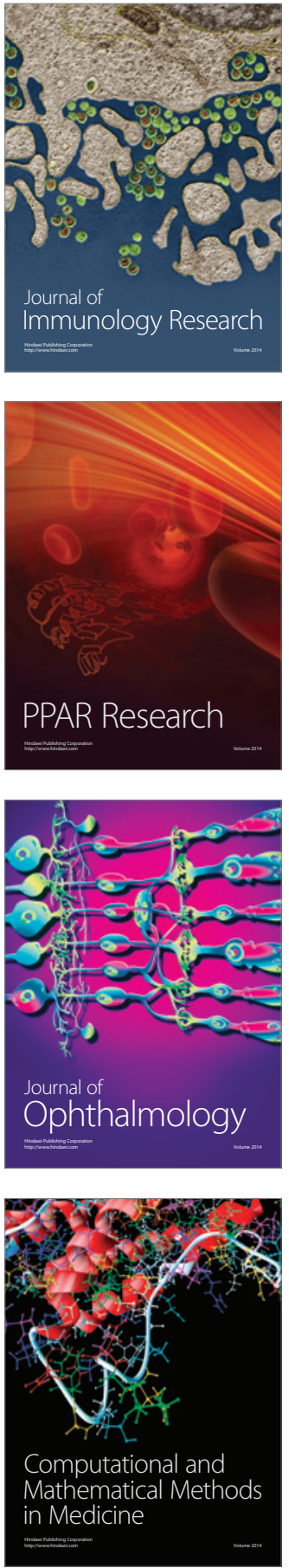

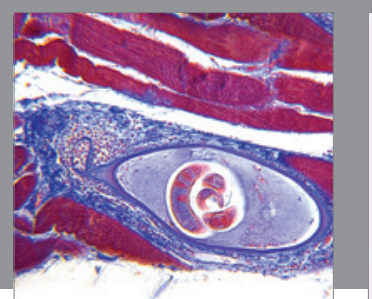

Gastroenterology Research and Practice

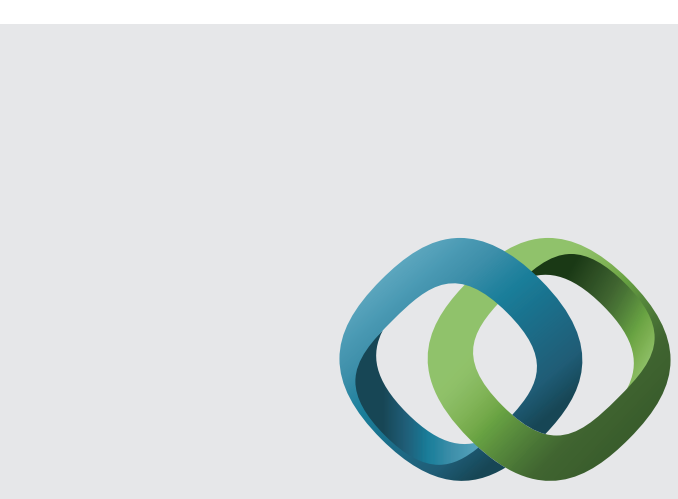

\section{Hindawi}

Submit your manuscripts at

http://www.hindawi.com
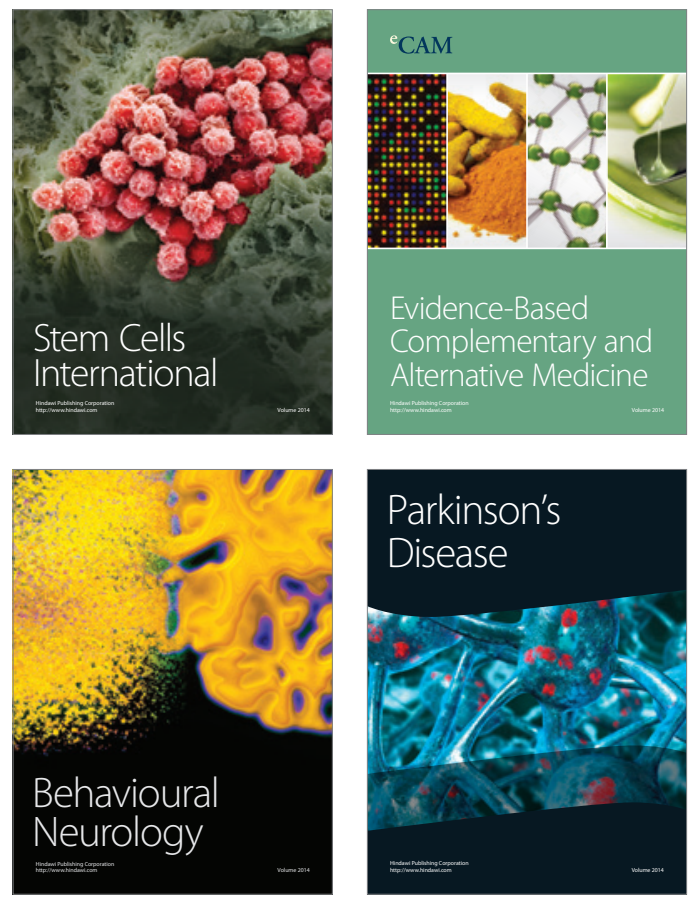
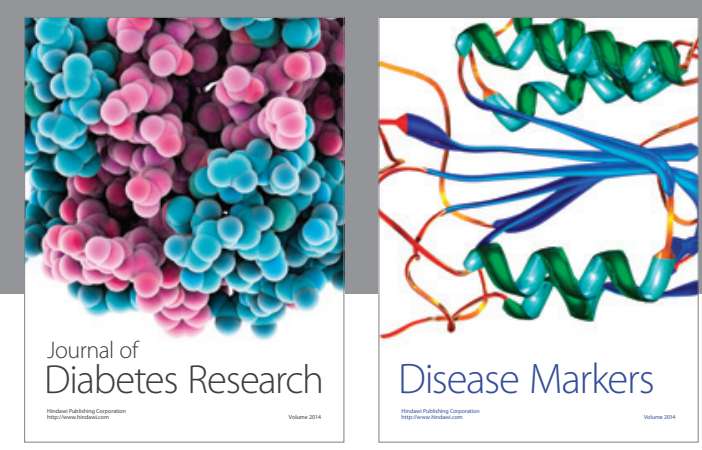

Disease Markers
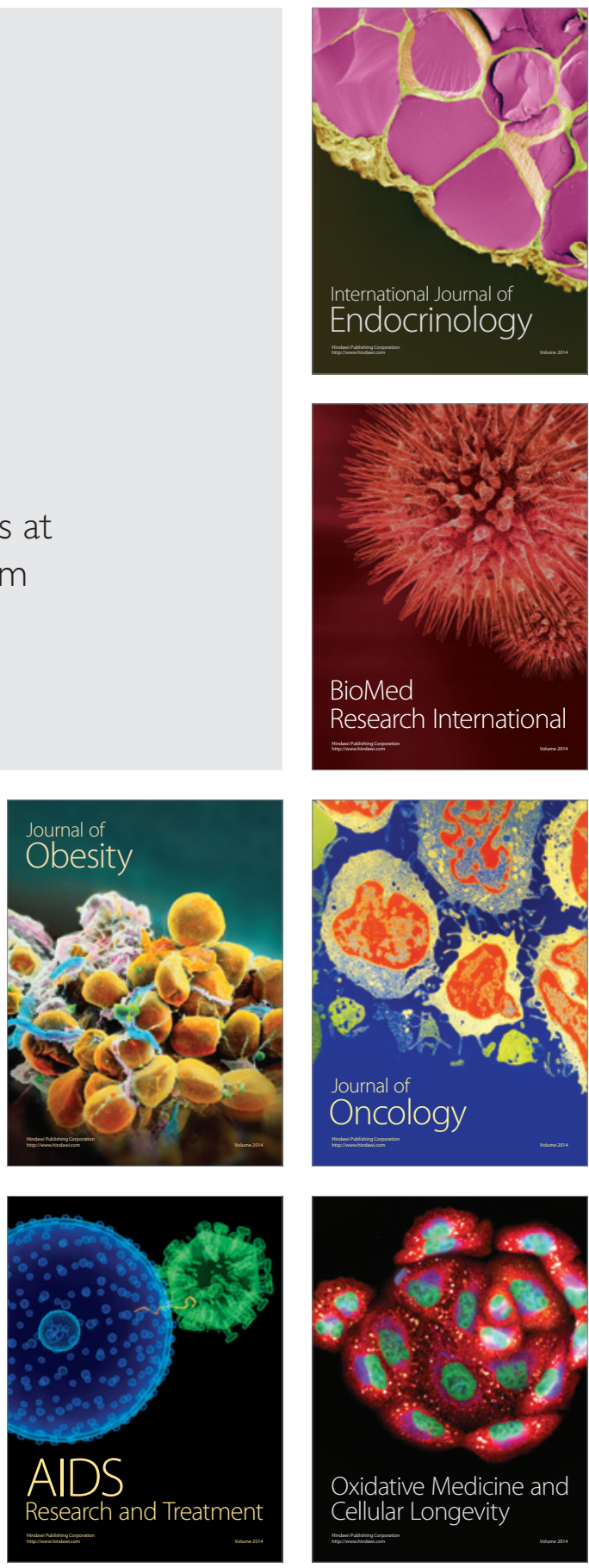